\title{
An overview of rural-urban migration in South Africa: its causes and implications
}

\author{
Victor Mlambo \\ University of Zululand, South Africa
}

\begin{abstract}
INTRODUCTION
South Africa's urban population is reported to be growing at alarming rates and it is projected that by 2050, a staggering 80 percent of the population will be residing in urban areas and this will surely have significant implications for rural development and growth. Debatably, one may opine that the government has not adequately invested in the development of rural areas as many are still characterised by the lack of infrastructure, limited access to educational and health services and limited economic opportunities needed for one's development. South Africa is rapidly urbanizing as more and more people are moving to urban areas mainly because of the perceived better living and working conditions that are ought to be present.
\end{abstract}

The United Nations projects that by 2030, a massive 71.3 percent of South Africa's population will be living in urban areas. While this is welcoming as it portrays the development of South Africa, it also paints a worrying picture about the future of South Africa's rural areas, as ruralurban migration becomes more and more prevalent, it is clear that these areas will continue to loss skilled and innovative people, which will further prolong the cycle of poverty and underdevelopment. Unfortunately, it is only recently that the South African government has realised the severity of the problem and has undertaken great dedication to addressing the growing problem through the development and implementation of policies that would spur development and growth in rural areas.

These policies are a combination of education, entrepreneurship and capacity development. The massive migration of people from rural areas has also exerted tremendous pressure on cities around the country and as a result, cities have witnessed an increase in traffic congestions, housing infrastructure backlogs and to some extent an increase in the crime levels. This implies that rural-urban migration in South Africa has been a great challenge to rural and urban areas. This study, therefore, analyses that factors responsible for rural-urban migration in South Africa and most importantly looks at the negative implications this phenomenon has for both rural and urban areas in the country.

\section{METHODOLOGY}

The study relied on extensively secondary data as a means of collecting relevant and required information. It employed strict textual analysis of the available literature relating to ruralurban migration in South Africa. The qualitative research approach was utilized in the course of this study. The purpose of this approach was to put into the context of understanding the underlying concepts and assumptions behind rural-urban migration in South Africa, to understand the causes and implication of those growing problem. Forrester (2010: 61-73) asserts that qualitative research uses methods such as participant observation or case studies which result in a narrative descriptive account of a setting or practice. various scholars have tried to understand the concept of rural-urban migration in South Africa and therefore there is plentiful information regarding the subject, while though some of this information may not comprehensively speak directly to the provision of rural-urban migration in South Africa a, 
they nonetheless offer views on the subject matter which will be utilized to further enrich the study.

\section{THEORETICAL SETTING}

The theoretical framework is the structure that can hold or support a theory of a research study. People move from region to region for different reasons, many scholars and authors from various disciplines have developed many theories to try and explain the migration process and its determinants. These theories are a combination of social sciences and economics and they outline many reasons as to what really motivates people to engage in migration.

Theories such as dual market theory, which see migration as a result of pull factors in developed countries and not by push factors in sending countries (Kogan, 2010: 14). The new economics of labour migration theory which states that the differences in wages between regions is the main reason for labor migration (Porumbescu, 2015: 55), and finally the social capital theory which assumes that networks created by migrants outside the place of destination are responsible and play a huge role in the migration process (Garip, 2008: 591617).

However for the purpose of this study, Lees Push/pull theory of migration will be used, Everest Lee, in his analysis of global migration trends, alluded that for people to migrate, there has to be push and pull factors (Digby, 2001: 167). Push factors are responsible for pushing one out of his place of origin, they include, political uncertainty, limited economic opportunity, poor health and educational facilities and poor security etc., and pull factors that those that pull people to the place of destination, they include better employment opportunities, better political climate and better health facilities etc. (Kivisto \& Faist, 2009: 37-39). In South Africa, undoubtedly, many people have left rural areas in search of employment, better healthcare and educational facilities, they have cited the lack of development in rural areas as that main driver of rural-urban migration, and therefore, Lee's push/pull theory is sufficient in guiding the study.

\section{REVIEWS OF LITERATURE}

BrandSouthAfrica (2014) opines that large towns and cities in South Africa produce over 80 percent of the country's Gross Domestic Product and metropolitan areas were growing twice as fast as other cities. Andries Nel, the deputy minister for the Department of Cooperative Governance and Traditional Affairs mentioned that while cities and rural areas in South Africa are advocating for closer integration, there is still a huge outflow of people from rural areas to urban, further pressuring the government to address this problem through policy intervention (Mears, 1997: 275). Between 1996 and 2012, 75 percent of all jobs created were created by metropolitan areas (SA Property News, 2015). Rees et al (2017: 23) mention that rural-urban migration is not only a South African problem because developed countries also experience huge volumes of people moving to places perceived to be better in terms of living and working. Carmel \& Cerami (2011: 30) state that in Europe, eastern European countries have seen an increase in cross-border migration, where citizens prefer living in western European countries, and in Nigeria, a huge concentration of people are found in Lagos and Abuja while in Ghana, Accra attracts numerous people, mainly those seeking employment. Therefore, rural-urban migration can be viewed in the context of international migration, where people migrate from underdeveloped to developed regions, mainly in search of economic opportunities and better standards of living. 
Melo \& Ames (2016: 2-9) alludes that just like international migration, rural-urban migration in most cases is motivated by the prevalence of better salaries and working conditions at the place of destination. Continentally, Africa is characterised by huge rates of migration, mainly with migrants seeking economic opportunities in neighbouring countries. In South Africa, over the years the country has seen a huge increase in teachers and medical professionals prefer to work in urban areas and regrettably, the government has been slow in addressing this growing problem (South African Council for Educators, 2011: 15).

Kok, 2006: 8-12) mentions that it was the 1886 discovery of gold in Johannesburg that ushered in a new wave of internal migration. In South Africa today, Predominately, rural provinces such as Mpumalanga, KwaZulu-Natal, Eastern Cape and Limpopo have become huge senders of people to work in these mines and ever since the discovery of gold in Johannesburg, the city has become a huge attraction for migrants from all over Africa as it is seen as a city with enormous potential and possibilities. Martine, 2012: 10-12) states that the legacy of apartheid in South Africa has also contributed to the increase in rural-urban migration because previously, certain race groups were prevented from travelling to certain areas and since the abolishment of apartheid, this has meant people are free to travel freely and hence we have seen an increase in internal migration in the country. South Africa is characterised by a high rate of temporary migration, where migrants travel to cities to seek employment and then remit money back home. Temporary migration represents a large proportion of the movement among the black population (Zuma, 2018: 3-6).

Shezi (2013: 110-112) mentions that contrary to popular believe, not all those who engage in rural-urban migration are unskilled people, over the years, skilled professionals working in rural areas have also started to favour working in predominantly urban places mainly because of working and living conditions and this has increasingly concerned authorities as it has severe implications for rural areas, especially in terms of the provision of skills and ensuring the effective rendering of services by the government. Migration is a response to the disequilibrium within a country's economic setting. Increasing inequality and economic disparity within South Africa, poverty and economic hardships further fuel rural-urban migration in the country. Between 2001 and 2011, South Africa's urban population increased from 57 to 63 percent, and cities such as Cape Town, Durban and Johannesburg have witnessed a significant increase inflow of people from across the country (Angelopulo, 2017: 65-69), furthermore, because rural areas lack the critical infrastructure needed for rapid development, they are too a great extent disconnected from development that happens in urban areas, hence with limited development, people opt to go in search of opportunities.

With the government recently prioritising rural development and empowerment, it remains to be seen whether policies and mechanisms developed by the government would be able to reduce the increasing rates of rural-urban migration in South Africa. Gauteng's transport MEC, Dr Ismail Vadi, stated that there are approximatively 12.9 million people in the province and that every month more than 20000 people come to the province to seek better life opportunities and mainly for employment purposes (Wakefield, 2015). Cross (2009) mentions that rural-urban migration in South Africa is characterised by four main corridors, mainly from Limpopo, Free-State, northern KwaZulu-Natal and Mpumalanga provinces all flowing into Gauteng province and form southern KwaZulu-Natal and Eastern Cape all flowing into the Western Cape. Gauteng by 2001, had the biggest influx of more than 1 million people while the Western Cape had more than 300000 (Donnelly, 2012). Financially embattled provinces such as Eastern Cape and Limpopo experience huge outflows of people while Gauteng and Western Cape experience a huge inflow of people, effectively contributing to the growing development of these provinces. The Average household income in Gauteng is more than R156 000 a year, 
whereas in the Western Cape it is R143 000. Limpopo remains the lowest with R56 000 per year (Donnelly, 2012). Therefore with provinces such as Western Cape and Gauteng growing rapidly, people will surely continue to engage in migration, mainly in search of better economic opportunities in these provinces and regrettably, if the government fails to rapidly prioritise rural development, South Africa will continue witnessing huge volumes of people migrating from rural areas to urban areas, therefore leaving the developmental aspects of rural areas in tatters.

\section{Causes of rural-urban migration in South Africa}

Migration in most cases is always motivated by ones desire to economically grow and develop through the search of economic opportunities, hence this is always the major factor encouraging people to engage in migration. However, these factors differ from country to country and from region to region, below are the major factors responsible for rural-urban migration in South Africa.

\section{Employment opportunities}

The Organisation for Economic Co-operation and Development (2011: 80) mentions that rapidly developing provinces like Gauteng and Western Cape, witness a huge inflow of people from across South Africa who are in search of employment opportunities. Gauteng and the Western Cape are characterised by fast-growing economies and mass industrialization, and there are prime targets for people who seek employment. Rural-urban migration in South Africa is largely motivated by economic reasons as rural areas cannot provide sufficient employment, people opt to venture into cities in search of opportunities. Undoubtedly, the number one factor responsible rural-urban migration in South Africa is employment opportunities.

\section{Educational and health services.}

Rural areas in South Africa are characterised by the insufficient provision of educational and health institutions. Page (2013) alludes that rural services are in disarray and are characterised by corruption, nepotism and poor accountability and service delivery, such problems entice people seek places which are characterised by better services, while they may not migrate to cities, people will ultimately seek places such as developing towns which are characterised by the efficient provision of services, which further compounds governments fight against rural-urban migration.

\section{Wage difference}

Working in an urban area increases the likelihood that one may earn more than a person who is working in a rural area and therefore this becomes a motivating factor for one to migrate to an urban area. Kok \& Collinson (2006) mention that many people from northern KwaZuluNatal travel to Gauteng to seek better remuneration as northern KwaZulu-Natal is characterised as a rural setting and hence cannot compare with urban areas in Gauteng in terms of salaries. Eastern Cape, KwaZulu-Natal and Limpopo are predominately rural provinces and the huge difference in salaries between urban and rural areas influences people to migrate to urban areas.

\section{Implications for rural-urban migration in South Africa}

Undoubtedly, the outflow of people from rural to urban areas will have far-reaching implications for both rural and urban areas and with government slow in reacting to the growing problem, rapidly developing provinces will surely continue witnessing a significant increase in the inflow of people seeking a better life. 


\section{Implications for rural areas \\ Loss of skill and innovation}

The migration of people deprives rural areas of skilled people who can work effectively to contribute to rural development. Rural areas lose critical thinkers, innovative people and future business leaders and this regrettably prolongs the underdevelopment and poverty in rural areas because there are no people with adequate skills and knowledge to contribute towards development and growth (Shezi, 2013: 112). The loss of skilled people is by far the negative impact that rural-urban migration for rural areas.

\section{Reduced availability of labour and resource underutilization.}

In South Africa, most people prefer working in urban areas which are seen as better in terms of living and economic opportunities, hence many skilled professionals leave rural areas. This, therefore, reduces the availability of skilled professionals to work on developmental projects aimed at developing rural areas, furthermore, the notion that better working conditions are only found in major cities, entices unskilled people to leave rural areas, hence prominent rural sector industries such as agriculture and extraction may find it cumbersome to attract the required labour, especially with the notion that rural salaries are not in line with those of urban areas (Amrevurayire \& Ojeh 2016: 8-12). The increase of rural migration also results in the underutilization of resources, if rural people remain behind and work together to contribute towards development, rural areas would develop and grow, however when they migrate, they migrate with their knowledge and technical know-how hence the resources meant for rural development may be under-utilized as there are no people to effectively use them. (Ghatak, 1995: 54-55).

\section{Implications for urban areas \\ Over population and government services}

Todes et al (2010: 331-348) states that Gauteng province is the smallest province in South Africa in terms of size and yet, it is the most populated in the country, it has the highest number of people from all over the country because they perceive that it is characterised by economic opportunity and personal growth. However, while the development of Gauteng has been welcomed, its rapid development has resulted in a significant population increase, which has led to an increase in crime and placed significant pressure on government resources. Kollamparambil, (2017: 12) states that the economic inequality between provinces in South Africa will continue to contribute to the inflow on people to Gauteng. The increase in people will strain government resources as the provisional government will have to cater for an increased population, which will to some extent impact of the effectiveness of serviced delivery.

\section{Housing provision and traffic congestion}

The increase in rural-urban migration has already strained the provision of housing services in cities like Johannesburg, and Cape Town and surely the continuous influx of people will put cities under severe pressure to accommodate the increase in population (Wakefield, 2015). Traffic congestion will also be problematic to manage, as more and more people migrate to cities, there is a high probability of vehicle congestions as people will purchase automobiles.

\section{Crime and unemployment}

The influx of more and more people into cities may contribute to the increase in crime level. As people migrate, not all of them find employment and in order to make a living, some may venture into crime, and surely, increased crime rates have been prevalent in cities like Johannesburg and Cape Town (Singh, 2016), while this is not to conclude that an increase in rural-urban migration results in increased crime in cities, there is, however, a strong 
correlation.

While people migrants may contribute effectively in the place of destination, rural areas also benefit because migrants send remittances that contribute to the migrant's family and upkeep. The government, from a policy point of view, has committed itself in allocating adequate resources to develop rural areas, these include upgrading health and educational infrastructure, enabling access to education and development of rural people through workshops. However, these are less likely to succeed as the root causes of rural-urban migration have not been addressed.

\section{CONCLUSIONS AND SUGGESTIONS}

Without sufficient and adequate investments in rural development, South Africa continues to witness an increase in rural-urban migration. Unfortunately, because of economic inequality within the country, provinces like Gauteng and Western Cape will undoubtedly continue to witness an increase in the inflow of people, mainly seeking employment opportunities. The study acknowledges the importance of addressing rural-urban migration as it possesses a significant threat to the development of rural areas, and therefore, the study suggests:

\section{Incentivise skilled professionals who opt to work in rural areas}

The government should ensure that rural areas are characterised by robust and wellfunctioning public services which are manned by skilled and competent personnel, however, with most skilled professionals preferring urban areas, the government should perhaps incentivise people who work in rural areas. This will encourage people to stay and work in rural areas and at the same time, it would improve the services rendered to rural communities. Rural communities in South Africa are too great extent disadvantaged when it comes to the accessing services, therefore, this approach will ensure competent people are employed and services are being rolled out effectively. It will also entice those in urban areas to relocate to rural areas.

\section{Coordinate policies with local/traditional leaders}

At times, there is a policy misalignment between government and community leaders in rural areas. As representatives of communities, local leaders understand the challenges faced by their communities, hence there should be open and clear channels of communication which will ensure that policy development an implementation is happening within the context of challenges identified by local leaders, hence this calls for increased communication and consultation between leaders and government.

\section{Promote agricultural development through skill development}

Rural provinces in South Africa possess large hectares or arable land which could be used for agricultural development, but because of the lack of skills and technical understanding, rural communities only engage in subsistence farming rather than commercial farming, therefore, for self-development and empowerment, the government should try and invest in capacity building workshops that would train people in the areas of framing and furthermore government should increase in financial support to established rural farmers as they can help in creating employment.

\section{Infrastructure development and eradicate poverty}

Communication, health, education and transportation infrastructure needs to be upgraded significantly in rural areas. Because of their economies scale, the government prioritises development of infrastructure in urban areas and because of the geographical setting of rural areas, upgrading Infrastructure may take time and may prove to be expensive. However, it is 
observable that rural areas lack the required Infrastructure to develop themselves and government should prioritise infrastructure development for rural areas in order to fight rural-urban migration. Poverty results in the migration of people as they go on the search for economic opportunities, the government in its quest to develop rural areas should prioritise policies that would contribute to the eradication of poverty while this may take time, it is however imperative that poverty is eradicated.

\section{References}

Amrevurayire, E. \& Ojeh, V. (2016). Consequences of rural-urban migration on the source region of ughievwen clan delta state Nigeria. European journal of geography, 7(3), pp.42-57.

Angelopulo, G. (2017). A Competitive Assessment of South Africa's Leading Cities-National, Continental and Global Perspectives. Strategic Review for Southern Africa, 39(1), p.65.

BrandSouthAfrica. (2014: January 30). South Africa's economy: key sectors. BrandSouthAfrica. Retrieved from: https://www.brandsouthafrica.com

Carmel, E. Cerami, A. \& Papadopoulos, T. eds. (2011). Migration and Welfare in the New Europe: Social protection and the challenges of integration. Policy Press. Bristol,

Cross, C. (2009: October 27). Migration trends and human settlements migration trends and human settlements some implications for service centres. Human Sciences Research Council. Retrieved from: www.hsrc.ac.za

Digby, B. (2001). Global Challenges. Heinemann Educational Press. Oxford

Donnelly, L. (2012: November 02). A country in a state of influx. Mail and Guardian. Retrieved from: https://mg.co.za

Forrester, M. (2010). Doing qualitative research in psychology: A practical guide. Sage. California

Garip, F. (2008). Social capital and migration: How do similar resources lead to divergent outcomes?. Demography, 45(3), pp.591-617.

Ghatak, S. (1995). Introduction to development economics (pp. 54-55). London: Routledge.

Kivisto, P. \& Faist, T. (2009). Beyond a border: The causes and consequences of contemporary immigration. Sage. California

Kogan, I. (2010). Working through Barriers: Host Country Institutions and Immigrant Labour Market Performance in Europe. Springer.

Kok, P. \& Collinson, M. (2006): Migration and urbanization in South Africa. Report 03-04-02, Pretoria: Statistics South Africa. Retrieved from: https:// statssa.gov.za.

Kok, P. ed. (2006). Migration in South and Southern Africa: dynamics and determinants. HSRC Press. Pretoria

Kollamparambil, U. (2017). Impact of internal in-migration on income inequality in receiving areas: A district level study of South Africa. The Journal of Development Studies, 53(12), 2145-2163.

Martine, G. (2012). The new global frontier: urbanization, poverty and environment in the 21st century. Earthscan. Routledge

Mears, R. (1997). Rural-Urban Migration or Urbanization in South Africa. South African Journal of Economics, 65(4), pp.275-283.

Melo, G. \& Ames, G. (2016, May). Driving Factors of Rural-Urban Migration in China. In 2016 Annual Meeting, July 31-August 2, 2016, Boston, Massachusetts (No. 235508). Agricultural and Applied Economics Association. Retrieved from: https://ageconsearch.umn.edu

Organisation for Economic Co-operation and Development. (2011). OECD Territorial Reviews OECD Territorial Reviews: The Gauteng City-Region, South Africa. OCED Publishing. Paris

Page, T. (2013: February 2013). Addressing South Africa's poor healthcare. Al Jazeera. Retrieved from: https://www.aljazeera.com

Porumbescu, A. (2015). Defining the new economics of labor migration theory boundaries: a sociological-level analysis of international migration. Revista de Stiinte Politice, (45), p.55.

Rees, P. Bell, M. Kupiszewski, M. Kupiszewska, D. Ueffing, P. Bernard, A. Charles-Edwards, E. \& Stillwell, J. (2017). The impact of internal migration on population redistribution: An international comparison. Population, Space and 
Place, 23(6).

SA Property News. (2015: November 23). Demographics influence South Africa's residential property market. SA Property News. Retrieved from: https://www.sapropertynews.com/

Shezi, X. (2013). The Impact of Migration on Rural Development: A Case Study of EMabhuqwini in Nkandla (Doctoral dissertation) University of KwaZulu-Natal, Durban, South Africa. Retrieved from: https://researchspace.ukzn.ac.za

Singh, K. (2016: June 15). Unemployed rural migrants end up committing crimes in urban areas - KZN South Coast CPF chair. News24. Retrieved from: https://www.news24.com

South African Council for Educators. (2011: June 2011). Teacher Migration in South Africa Advice to the Ministries of Basic and Higher Training. SACE. Retrieved from: http://sace.org.za/

Todes, A. Kok, P. Wentzel, M. Van Zyl, J. \& Cross, C. (2010). Contemporary South African urbanization dynamics. In Urban forum (Vol. 21, No. 3, pp. 331-348). Springer Netherlands.

Wakefield, A. (2015: June 18). Urban migration 'putting pressure' on Gauteng's public transport. Retrieved from: https://www.news24.com

Zuma, N. (2018: November 1-2). Rural-urban Migration in South Africa. China institute for reform and development economic policy forum. Retrieved from: https://ageconsearch.umn.edu 